\title{
Front Matter: Volume 7491
}

, "Front Matter: Volume 7491," Proc. SPIE 7491, PIAGENG 2009: Remote Sensing and Geoscience for Agricultural Engineering, 749101 (10 July 2009); doi: $10.1117 / 12.837691$

SDIE Event: International Conference on Photonics and Image in Agriculture Engineering (PIAGENG 2009), 2009, Zhangjiajie, China 


\title{
PROCEEDINGS OF SPIE
}

\section{PIAGENG 2009 \\ Remote Sensing and Geoscience for Agricultural Engineering}

\author{
Honghua Tan \\ Qi Luo \\ Editors
}

11-12 July 2009

Zhangjiajie, China

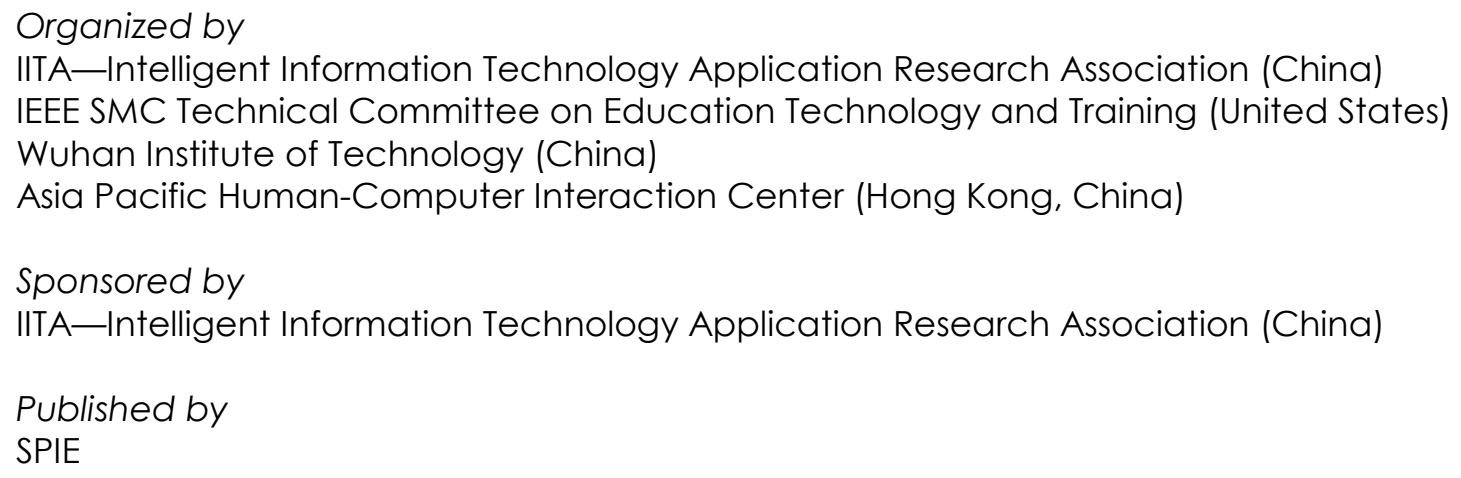


The papers included in this volume were part of the technical conference cited on the cover and title page. Papers were selected and subject to review by the editors and conference program committee. Some conference presentations may not be available for publication. The papers published in these proceedings reflect the work and thoughts of the authors and are published herein as submitted. The publisher is not responsible for the validity of the information or for any outcomes resulting from reliance thereon.

Please use the following format to cite material from this book:

Author(s), "Title of Paper," in PIAGENG 2009: Remote Sensing and Geoscience for Agricultural Engineering, edited by Honghua Tan, Qi Luo, Proceedings of SPIE Vol. 7491 (SPIE, Bellingham, WA, 2009) Article CID Number.

ISSN 0277-786X

ISBN 9780819478023

Published by

SPIE

P.O. Box 10, Bellingham, Washington 98227-0010 USA

Telephone +1 3606763290 (Pacific Time) · Fax +1 3606471445

SPIE.org

Copyright (C) 2009, Society of Photo-Optical Instrumentation Engineers

Copying of material in this book for internal or personal use, or for the internal or personal use of specific clients, beyond the fair use provisions granted by the U.S. Copyright Law is authorized by SPIE subject to payment of copying fees. The Transactional Reporting Service base fee for this volume is $\$ 18.00$ per article (or portion thereof), which should be paid directly to the Copyright Clearance Center (CCC), 222 Rosewood Drive, Danvers, MA 01923. Payment may also be made electronically through CCC Online at copyright.com. Other copying for republication, resale, advertising or promotion, or any form of systematic or multiple reproduction of any material in this book is prohibited except with permission in writing from the publisher. The CCC fee code is 0277-786X/09/ $\$ 18.00$.

Printed in the United States of America.

Publication of record for individual papers is online in the SPIE Digital Library.

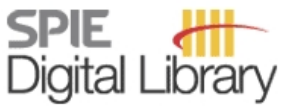

SPIEDigitalLibrary.org

Paper Numbering: Proceedings of SPIE follow an e-First publication model, with papers published first online and then in print and on CD-ROM. Papers are published as they are submitted and meet publication criteria. A unique, consistent, permanent citation identifier (CID) number is assigned to each article at the time of the first publication. Utilization of CIDs allows articles to be fully citable as soon they are published online, and connects the same identifier to all online, print, and electronic versions of the publication. SPIE uses a six-digit CID article numbering system in which:

- The first four digits correspond to the SPIE volume number.

- The last two digits indicate publication order within the volume using a Base 36 numbering system employing both numerals and letters. These two-number sets start with 00, 01, 02, 03, 04, $05,06,07,08,09,0 A, 0 B \ldots 0 Z$, followed by 10-1Z, 20-2Z, etc.

The CID number appears on each page of the manuscript. The complete citation is used on the first page, and an abbreviated version on subsequent pages. Numbers in the index correspond to the last two digits of the six-digit CID number. 


\section{Contents}

ix Conference Committee
xi Introduction

PIAGENG 2009: REMOTE SENSING AND GEOSCIENCE FOR AGRICULTURAL ENGINEERING

749102 GIS-based fine spatial climate ecological regionalization of sweet orange in the Three Gorges reservoir area [7491-01]

Y. Gao, Z. Chen, Chongqing Institute of Meteorological Science (China); H. Ju, Institute of Environment and Sustainable Development in Agriculture (China); S. Yang, Y. Tang, Chongqing Institute of Meteorological Science (China)

749103 Agricultural environment information monitoring instruments based on integrated intelligent sensors [7491-02]

G. Yu, Z. Sha, M. Cai, Hebei Univ. of Science and Technology (China)

749104 Study on strain sensing of asymmetric Mach-Zehnder fiber filter [7491-03]

C. Liu, H. Ye, College of Heilongjiang Province (China)

749105 Discussion of GPS/RTK in fighting drought [7491-04]

Q. Wang, Henan Polytechnic Univ. (China); L. Fang, Zhejiang Tunnel Engineering Co.

(China); K. Li, Henan Polytechnic Univ. (China) and Chang'an Univ. (China); P. Zang, Henan

Polytechnic Univ. (China)

$749106 \quad$ Numerical modeling and analysis of the environment in a mechanically ventilated greenhouse [7491-05]

F. Wu, Zhejiang Univ. of Technology (China) and Zhejiang Univ. (China); L. Zhang, F. Xu, Q. Ai,

J. Chen, Zhejiang Univ. of Technology (China)

749107 Research on the relationship between soil erosion and landscape pattern in the Wuyuer River basin based on GIS [7491-06]

W. Wang, Northeast Institute of Geography and Agroecology (China) and Graduate School of the Chinese Academy of Sciences (China); S. Zhang, Y. Li, Northeast Institute of Geography and Agroecology (China); R. Deng, Northeast Institute of Geography and Agroecology (China) and Graduate School of the Chinese Academy of Sciences (China); Y. Yan, Nanjing Univ. of Information and Technology (China)

749108 Algorithm research showing high-dynamic GPS software receiver [7491-07] H. Hu, N. Wei, East China JiaoTong Univ. (China)

749109 Interpolation and fitting algorithms for GPS satellite orbit [7491-08] H. Hu, L. Fang, East China JiaoTong Univ. (China)

$74910 \mathrm{OA}$ Discrete Hadamard transformation algorithm's parallelism analysis and achievement [7491-09]

H. Hu, East China JiaoTong Univ. (China) 
$7491 \mathrm{OB}$ Temporal and spatial changes analysis of arable land in Zhongshan city based on GIS and RS [7491-10]

Y. Fang, Huanggang Normal Univ. (China); H. Zhang, Tianjin Institute of Urban Construction (China)

7491 OC Land use conversion and gravity center analysis in the coastal area of the Pearl River Estuary based on GIS and RS [7491-11]

Y. Fang, Huanggang Normal Univ. (China); H. Zhang, Tianjin Institute of Urban Construction (China)

7491 OD Analysis of construction land expansion during the urbanization process in Dongguan city [7491-12]

D. Wu, L. Chen, Huanggang Normal Univ. (China)

7491 OE Asynchronous web geological map tag system based on Ajax [7491-13]

C. Deng, L. Xue, W. Li, Jilin Univ. (China); Z. Zhou, Northeast Normal Univ. (China)

7491 OF The application of ESDA and GIS in analysis of regional rural economy [7491-14] W. Liao, H. Yang, Guangxi Univ. (China)

7491 OG GIS-based quality analysis on the cultivated land resources in poor areas of China [7491-15] L. Liu, Institute of Geographic Sciences and Natural Resources Research (China), Graduate School of the Chinese Academy of Sciences (China), and Shandong Provincial Audit Office (China); Y. J. Wang, J. F. Han, Institute of Geographic Sciences and Natural Resources Research (China)

$7491 \mathrm{OH} \quad$ GIS-based poverty and population distribution analysis in China [7491-16]

J. Cui, Y. Wang, H. Yan, Institute of Geographic Sciences and Natural Resources Research (China)

$74910 \mathrm{O}$ The principle and main structure design on national database of poverty, environment, and development in China [7491-17]

Y. Wang, X. Feng, Z. Yu, J. Cui, Institute of Geographic Sciences and Natural Resources Research (China)

$74910 \mathrm{~J}$ The design and research of poverty alleviation monitoring and evaluation system: a case study in the Jiangxi province [7491-18] H. Mo, Institute of Geographic Sciences and Natural Resources Research (China), Guangxi Teachers Education Univ. (China), and Graduate School of the Chinese Academy of Sciences (China); Y. Wang, Z. Yu, Institute of Geographic Sciences and Natural Resources Research (China)

7491 OK Development of a distributed agricultural drought prediction model based on TOPMODEL and GIS [7491-19]

J. Xu, Sichuan Agricultural Univ. (China), Institute of Atmospheric Physics (China), and Graduate School of the Chinese Academy of Sciences (China); W. Zhang, Institute of Atmospheric Physics (China); C. Wang, X. Zhu, Sichuan Agricultural Univ. (China); J. Chen, Institute of Atmospheric Physics (China) 
7491 OL Development of a soil moisture prediction model based on Xinanjiang model and GIS [7491-20]

J. XU, Sichuan Agricultural Univ. (China), Institute of Atmospheric Physics (China), and Graduate School of the Chinese Academy of Sciences (China); W. Zhang, Institute of Atmospheric Physics (China); C. Wang, Sichuan Agricultural Univ. (China); Z. Zheng, J. Chen, Institute of Atmospheric Physics (China)

7491 OM Study on temporal variation and spatial distribution for rural poverty in China based on GIS [7491-21]

X. Feng, Institute of Geographic Sciences and Natural Resources Research (China); X. XU, Institute of Geographic Sciences and Natural Resources Research (China) and Hohai Univ. (China); Y. Wang, J. Cui, H. Mo, L. Liu, H. Yan, Y. Zhang, J. Han, Institute of Geographic Sciences and Natural Resources Research (China)

$74910 N \quad$ Study on the shelterbelt effects on crop condition using RS and GIS [7491-22] R. Deng, Northeast Institute of Geography and Agroecology (China) and Graduate School of the Chinese Academy of Sciences (China); S. Zhang, Y. Li, Northeast Institute of Geography and Agroecology (China); W. Wang, Northeast Institute of Geography and Agroecology (China) and Graduate School of the Chinese Academy of Sciences (China)

749100 The choice of adjustment programmes of China's existing coal mine safety supervision system [7491-23]

Y.-L. Liu, A-H. He, Hebei Univ. of Engineering (China)

7491 OP A CMOS low-power voltage control oscillator applied in the GPS RF receiver [7491-24] Z. Cai, East China Institute of Technology (China) and Southeast Univ. (China); X. Chen, J. Zou, X. Zhu, East China Institute of Technology (China)

$74910 Q \quad$ Gray-Markov-model-based prediction and analysis on urban water use [7491-25] W. Jiang, Y. Zhang, J. Xie, Jinan Univ. (China)

7491 OR Evaluation of heavy metal accumulation in greenhouse soils in Shenyang, Northeast China [7491-26]

J. Wang, Institute of Applied Ecology (China) and Graduate School of the Chinese Academy of Sciences (China); X. Chen, Y. Shi, Institute of Applied Ecology (China); M. Zhao, Institute of Applied Ecology (China) and Graduate School of the Chinese Academy of Sciences (China); F. Meng, Institute of Applied Ecology (China) and Liaoning Science and Technology Agency (China)

7491 OS Driving force analysis of LUCC and forecast method based on remote sensing in coal mining area [7491-27]

H. Xie, X. Gao, X. Lu, Huaihai Institute of Technology (China)

7491 OT A multivariable approach for land cover mapping with MODIS data: an assessment of Sanjiang Plain, China [7491-28]

H. Cai, Northeast Institute of Geography and Agroecology (China) and Graduate Univ. of the Chinese Academy of Sciences (China); S. Zhang, Northeast Institute of Geography and Agroecology (China) 
7491 OU The spatial-temporal change and forecast of farmland landscape in Shenyang city based on GIS and RS [7491-29]

R. Zhou, Institute of Applied Ecology (China) and Graduate Univ. of the Chinese Academy of Sciences (China); Y. Li, Y. Hu, Institute of Applied Ecology (China); X. Wu, Yantai Institute of Coastal Zone Research for Sustainable Development (China)

7491 OV Estimation methods for GPS kinematic data processing [7491-30]

G. Chen, X. Pan, China Univ. of Geosciences (China)

7491 OW Research on agricultural ecology and environment analysis and modeling based on RS and GIS [7491-31]

W. Zhang, H. Chen, M. Wang, Shijiazhuang Railway Institute (China)

7491 OX Land use/cover change and its driving forces analysis during the last $\mathbf{5 0}$ years in the Three Gorges Reservoir area: a case study in the Wanzhou District [7491-32]

W. Xian, Chengdu Univ. of Information Technology (China), Chengdu Institute of Mountain Disaster and Environment (China), and Graduate Univ. of the Chinese Academy of Sciences (China); H. Shao, Chengdu Univ. of Technology (China); W. Zhou, Chengdu Institute of Mountain Disaster and Environment (China); J. Zhou, Sichuan Normal Univ. (China)

7491 OY A study on eco-environmental vulnerability of mining cities: a case study of Panzhihua city of Sichuan province in China [7491-33]

H. Shao, Chengdu Univ. of Technology (China); W. Xian, Chengdu Univ. of Information Technology (China); W. Yang, Chengdu Univ. of Technology (China)

$74910 Z$ A GIS-based model for estimating regional potential evapotranspiration in complex terrains [7491-34]

X. Zhou, Y. Yang, X. Hao, Institute of Genetics and Developmental Biology (China)

749110 A novel dual module remote video monitoring system based on TD-SCDMA and CDMA2000 $1 X$ [7491-35]

Z. Tian, Q. Zhang, W. He, Q. Li, Chongqing Univ. of Posts and Telecommunications (China)

749111 Ecological landscape classification and dynamic change mapping in the Taoer River basin, Northeast China [7491-36]

J. Yang, Northeast Institute of Geography and Agroecology (China) and Graduate Univ. of the Chinese Academy of Sciences (China); S. Zhang, Northeast Institute of Geography and Agroecology (China)

749112 Effects of tillage on the Fe oxides activation in soil [7491-37]

G. Chi, Institute of Applied Ecology (China) and Graduate Univ. of the Chinese Academy of Sciences (China); X. Chen, Y. Shi, Institute of Applied Ecology (China); J. Wang, T. Zheng, Institute of Applied Ecology (China) and Graduate Univ. of the Chinese Academy of Sciences (China)

749113 Analysis on the rural house reconstruction agreement in earthquake disaster rural areas [7491-38]

W. Zhao, H. Xu, Beijing Normal Univ. (China); Y. Zhang, Ctr. for Earth Observation and Digital Earth (China); C. Xie, Beijing Normal Univ. (China) 
749114 Land resources and sustainable utilization in China [7491-39]

W. Zhao, H. XU, G. Jiang, Beijing Normal Univ. (China); Y. Zhang, Ctr. for Earth Observation and Digital Earth (China)

749115 Assessment of ecological footprint of land use in Chongqing, China [7491-42]

M. Li, Southwest Univ. (China) and Chongqing Univ. (China); B. Li, Chongqing Univ. (China)

Author Index 
Downloaded From: https://www.spiedigitallibrary.org/conference-proceedings-of-spie on 26 Apr 2023

Terms of Use: https://www.spiedigitallibrary.org/terms-of-use 


\title{
Conference Committee
}

\author{
Conference Chairs
}

Honghua Tan, Wuhan Institute of Technology (China)

Fan Yang, Wuhan Institute of Technology (China)

Committee Chairs

Weitao Zheng, Wuhan University of Technology (China)

Ben Kwang-Mong Sim, Hong Kong Baptist University

(Hong Kong, China)

Program Committee

Shao Xi, Nanjing University of Posts and Telecommunications (China)

Xueming Zhang, Beijing Normal University (China)

Peide Liu, Shangdong Economic University (China)

Dariusz Krol, Wroclaw University of Technology (Poland)

Jason J. Jung, Yeungnam University (Korea, Republic of)

Paul Davidsson, Blekinge Institute of Technology (Sweden)

Longbing Cao, University of Technology, Sydney (Australia)

Huaifeng Zhang, University of Technology, Sydney (Australia)

Qian Yin, Beijing Normal University (China)

\section{Session Chairs}

$1 \quad$ Image Processing in Agricultural Engineering Qi Luo, Wuhan Institute of Technology (China)

2 Photonics in Agricultural Engineering Qi Luo, Wuhan Institute of Technology (China)

3 GIS, GPS, RS in Agricultural Engineering

Weitao Zheng, Wuhan University of Technology (China)

$4 \quad$ Wireless and Optical Communications in Agricultural Engineering Honghua Tan, Wuhan Institute of Technology (China)

5 Agricultural Decision Support and Simulation Systems Honghua Tan, Wuhan Institute of Technology (China)

6 Intelligent Monitoring and Control/ICT Applications in Rural Areas Honghua Tan, Wuhan Institute of Technology (China) 
$7 \quad$ Sensor Technology in Agricultural Engineering

Weitao Zheng, Wuhan University of Technology (China)

8 Other Related Information Technology in Agricultural Engineering Honghua Tan, Wuhan Institute of Technology (China) 


\section{Introduction}

Information technologies such as image processing, photonics, GIS, and so on are becoming more and more important for rural development. All commercial crop and animal production systems are potential users for intelligent Information technology products. Many intelligent information technology systems have been developed to help farmers, extension workers, and administrators. Intelligent information technology will provide powerful means for the transformation of agriculture. Many countries have established associations or research centers for information technology in agriculture. It is necessary for experts from developed and developing countries to exchange ideas.

Welcome to the PIAGENG 2009 conference, held 11-12 July 2009, in Zhangjiajie, China. The 2009 International Conference on Photonics and Image in Agriculture Engineering is cosponsored by the Intelligent Information Technology Application Research Association (IITA Association), IEEE SMC TC on Education Technology and Training (USA), the Wuhan Institute of Technology (China), and Asia Pacific Human-Computer Interaction Research Center of Hong Kong. PIAGENG 2009 has seven sessions: Image Processing in Agricultural Engineering; Photonics in Agricultural Engineering; GIS, GPS, RS in Agricultural Engineering; Wireless and Optical Communications in Agricultural Engineering; Agricultural Decision Support and Simulation Systems; Intelligent Monitoring and Control/ICT Applications in Rural Areas; Sensor Technology in Agricultural Engineering; and Other related information technology in Agricultural Engineering.

The purpose of PIAGENG 2009 is to bring together researchers and practitioners from academia, industry, and government to exchange their research ideas and results, and to discuss the state of the art in the areas of the conference.

We thank the SPIE staff for their enthusiastic support our conference, and for their editorial work on these proceedings. We would also like to thank the program chairs, organization staff, and the members of the program committees for their hard work.

We hope that PIAGENG 2009 will be successful and enjoyable to all participants. We look forward to seeing all of you next year at the PIAGENG 2010.

Honghua Tan 
Downloaded From: https://www.spiedigitallibrary.org/conference-proceedings-of-spie on 26 Apr 2023

Terms of Use: https://www.spiedigitallibrary.org/terms-of-use 